\title{
Acute pancreatitis associated with a nontraumatic, intramural duodenal hematoma
}

Intramural duodenal hematoma is a rare disease, first described in 1838 by MacLauchlan. More than $70 \%$ of intramural duodenal hematomas are secondary to blunt abdominal trauma [1]. Nontraumatic intramural duodenal hematoma was first reported by Sutherland in 1904 and is associated with anticoagulation (most commonly) or antiplatelet therapy, coagulation disorders, and endoscopic hemostasis. An association between intramural duodenal hematoma and acute pancreatitis has been rarely reported [2].

A 64-year-old man presented with a 1-day history of abdominal pain and postprandial vomiting. He had had an acute myocardial infarction 6 months ago, and had been treated with a coronary drug-eluting stent and dual antiplatelet therapy (aspirin and clopidogrel). His alcohol intake was $30 \mathrm{~g} /$ day. There was no history of pancreatitis, abdominal trauma, or hypertriglyceridemia. Laboratory investigations revealed hemoglobin $15.4 \mathrm{~g} / \mathrm{dL}$, international normalized ratio (INR) 1.17, amylase $724 \mathrm{IU} / \mathrm{L}$, and lipase $1095 \mathrm{IU} / \mathrm{L}$. Abdominal ultrasound was unremarkable (pancreas partially observed). He was admitted with the diagnosis of acute pancreatitis of unknown etiology (Ranson's criteria 1). At 24 hours after admission, the hemoglobin level dropped by $3.8 \mathrm{~g} / \mathrm{dL}$, and at 48 hours three Ranson's criteria were present. Contrast-enhanced abdominal computed tomography (CT) showed diffuse enlargement of the pancreas and an intramural duodenal hematoma in the duodenum ( $\bullet$ Fig. 1). Upper gastrointestinal endoscopy revealed reddish bulging in the duodenum ( $\bullet$ Fig. 2). The planned conservative treatment was successful and the patient was discharged 14 days later. A follow-up CT 1 month later showed significant reduction in the size of the hematoma ( $\bullet$ Fig. 3).

Nontraumatic intramural duodenal hematoma is uncommon and occurs mainly in patients with risk factors for bleeding. The CT findings of mural hyperdensity within an area of circumferential thickening of the small bowel, causing luminal narrowing, are characteristic of intramural duodenal hematoma [3]. Acute pan-
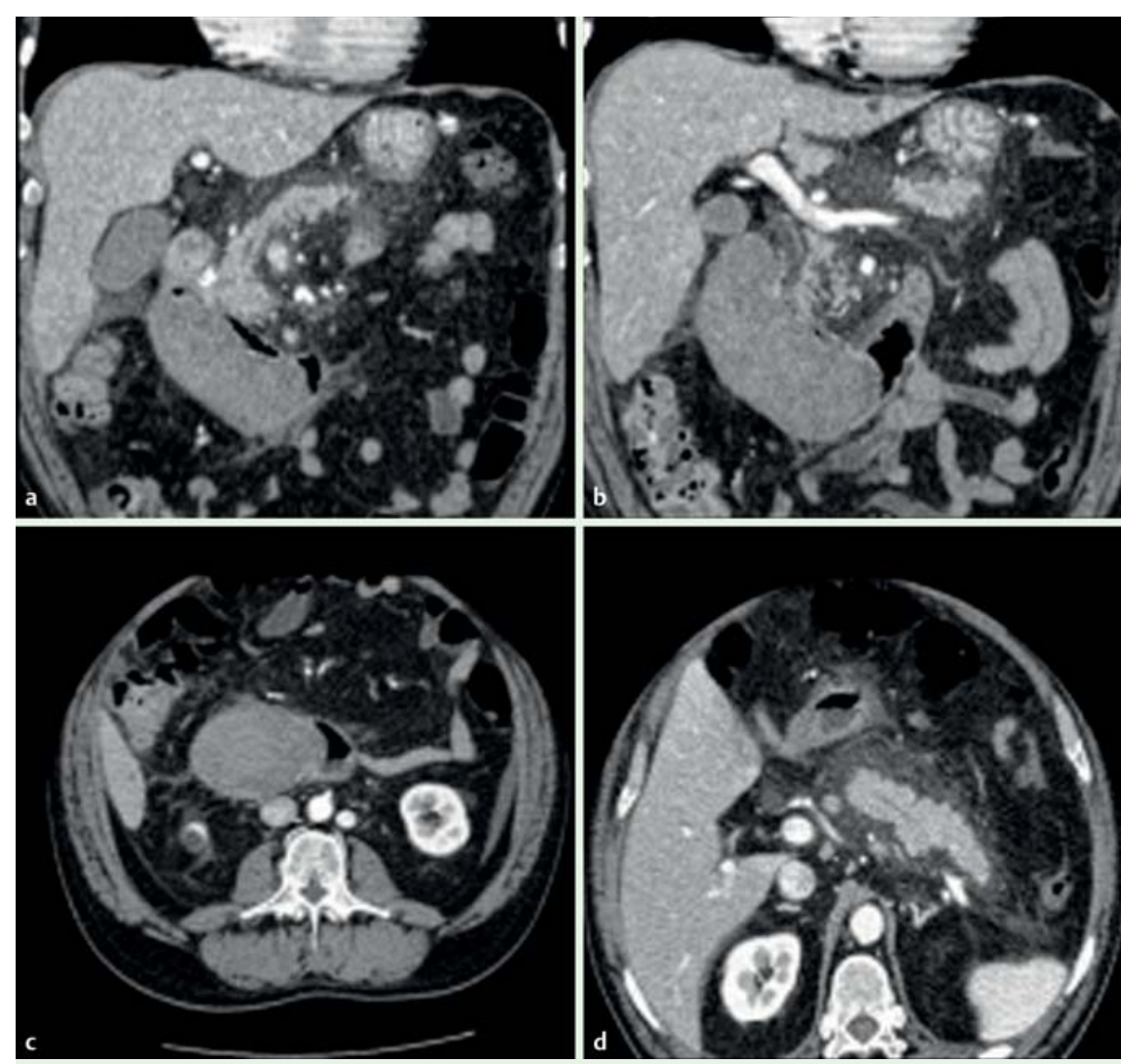

Fig. 1 a-c Contrast-enhanced abdominal CT in a 64-year-old man with a 1-day history of abdominal pain and postprandial vomiting. There is a hyperdense expansive lesion $(10 \times 6 \mathrm{~cm})$, without contrast enhancement in the arterial phase, in the second and third portions of the duodenum, with mass effect on the duodenal lumen and pancreatic tissue, suggestive of intramural duodenal hematoma. $\mathbf{d}$ Diffuse enlargement of the pancreas and increased density of peripancreatic fat tissue. The gastroduodenal artery and pancreatic arterial arcade showed no irregularities.

creatitis secondary to intramural duodenal hematoma is probably due to compression of the pancreas and/or obstruction of the duodenal papilla. Patients with nonextensive intramural hematomas generally have a good outcome with conservative treatment $[3,4]$.

Endoscopy_UCTN_Code_CCL_1AZ_2AF

Competing interests: None

\section{N. Veloso, P. Amaro, M. Ferreira, J. M. Romãozinho, C. Sofia}

Gastroenterology Intensive Care Unit, Gastroenterology Department, Coimbra University Hospital, Coimbra, Portugal

\section{References}

1 Jewett TC Jr, Caldarola V, Karp MP et al. Intramural hematoma of the duodenum. Arch Surg 1988; 123: $54-58$

2 Ma JK, Ng KK, Poon RT et al. Pancreatic-induced intramural duodenal haematoma. Asian J Surg 2008; 31: 83-86

3 Abbas MA, Collins JM, Olden KW. Spontaneous intramural small-bowel hematoma: imaging findings and outcome. AJR Am J Roentgenol 2002; 179: 1389-1394

4 Abbas MA, Collins JM, Olden KW et al. Spontaneous intramural small-bowel hematoma: clinical presentation and long-term outcome. Arch Surg 2002; 137: 306 - 310 


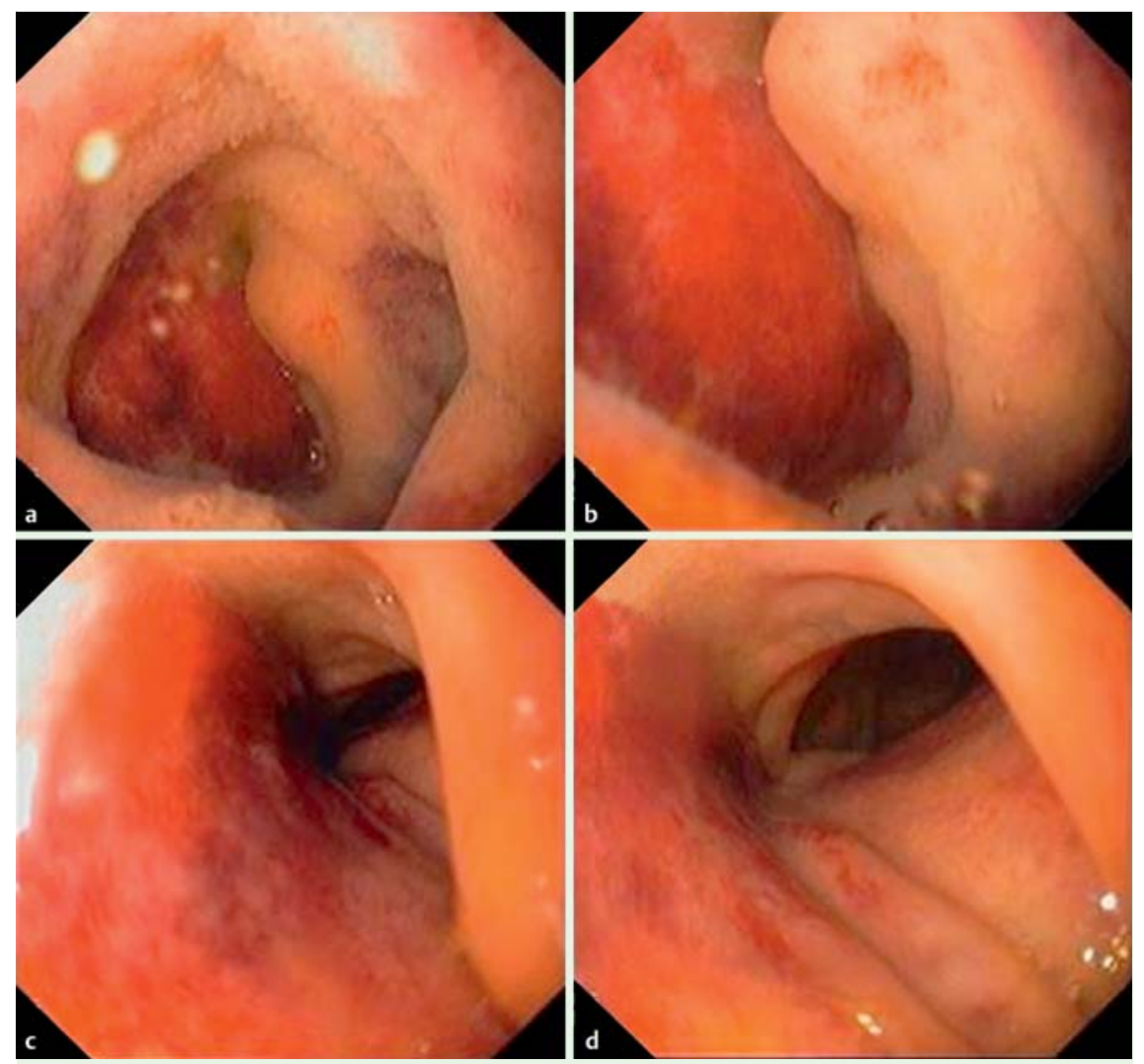

\section{Bibliography}

DOI http://dx.doi.org/

10.1055/s-0032-1325969

Endoscopy 2013; 45: E51-E52

(c) Georg Thieme Verlag KG

Stuttgart · New York

ISSN 0013-726X

\section{Corresponding author}

\section{N. Veloso}

Department of Gastroenterology

Hospital Espírito Santo

Évora

Portugal

Fax: +351-2667-40117

nuno_veloso@hotmail.com

Fig. 2 Upper gastrointestinal endoscopy showing soft, reddish bulging of the duodenum. a, b The duodenal bulb. c, $\mathbf{d}$ The second and third parts of the duodenum.

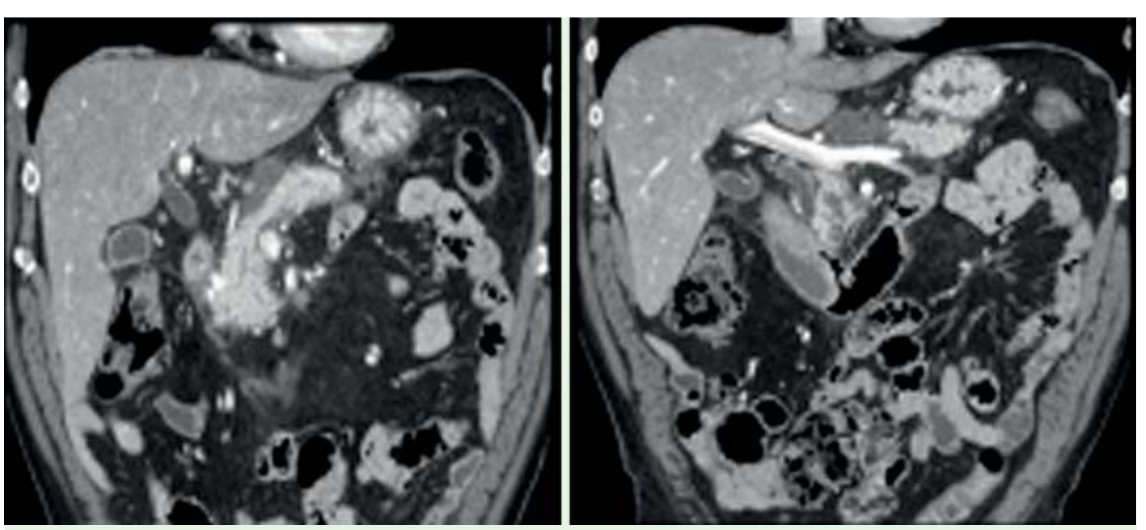

Fig. 3 Follow-up computed tomography (CT) (1 month after discharge) showing reduction in the size of the hematoma $(2 \times 1 \mathrm{~cm})$. 